\title{
Obsessive-Compulsive Disorder in a 19-Year-Old Female Adolescent With Turner Syndrome
}

\author{
Surinder S. Moonga ${ }^{\mathrm{a}, \mathrm{b}}$, Aaron Pinkhasov ${ }^{\mathrm{a}}$, Deepan Singh ${ }^{\mathrm{a}, \mathrm{c}}$
}

\begin{abstract}
Obsessive-compulsive disorder (OCD) in patients with Turner syndrome (TS) is an uncommon neuropsychiatric presentation that has not been well characterized in the scientific literature. Though no clear psychiatric component is syndromic to TS, the clinical manifestations of certain neuropsychiatric disorders, including mood, anxiety and eating disorders, have all been well documented in patients with TS. However, the presence of OCD in these patients has not been previously described. This report details a 19-year-old TS patient who presented with OCD since the age of 13, comorbid with several other psychiatric pathologies, including bipolar I disorder, anorexia nervosa and attention deficit hyperactivity disorder (ADHD). It will also discuss those comorbidities in relation to the patient's genetic syndrome and mention the contribution it makes to her multiple disabilities diagnosis as well as her patient-specific therapy. Patients with TS often present to treating physicians for overwhelming somatic complaints, likely resulting in poor recognition of psychiatric disorders. Thus, OCD may be significantly underdiagnosed in patients with TS and should be explored by clinicians treating this vulnerable population.
\end{abstract}

Keywords: Obsessive-compulsive disorder; Turner syndrome; Adolescent

\section{Introduction}

Obsessive-compulsive disorder (OCD) is a relatively common disorder, with a likely underestimated lifetime prevalence of $1-3 \%$ [1]. Patients with OCD suffer from either obsessions, compulsions or both [2]. Obsessions refer to recurrent intrusive/unwanted thoughts, images or urges (e.g. fear of contamination); compulsions are repetitive physical/mental actions

Manuscript submitted September 12, 2017, accepted September 27, 2017

a Department of Behavioral Health, NYU Winthrop Hospital, Mineola, NY 11501, USA

bStony Brook School of Medicine, Stony Brook, NY 11794, USA

${ }^{\mathrm{c} C o r r e s p o n d i n g ~ A u t h o r: ~ D e e p a n ~ S i n g h, ~ D e p a r t m e n t ~ o f ~ B e h a v i o r a l ~ H e a l t h, ~}$ NYU Winthrop Hospital, 222 Station Plaza North, Suite 350A, Mineola, NY 11501, USA. Email: DSingh1@nyuwinthrop.org

doi: https://doi.org/10.14740/jocmr3195w that are often responses to the obsessions or rigid rituals of their own accord (e.g. disproportionate hand-washing behaviors) [3]. Regarding its biologic predisposition, OCD is currently thought to have a complex inheritance pattern, with good evidence supporting a genetic basis in combination with psychosocial risk factors [4]. There have been studies linking genes on the $\mathrm{X}$ chromosome to OCD in families with several hoarding members [4]. However, OCD syndromic to a chromosomal disorder has not been well described in the literature.

Turner syndrome (TS) is a relatively common chromosomal disorder ( 1 in 2,000 live born females) with clinical manifestations most commonly described in somatic systems, including cardiac, endocrine, skeletal and reproductive systems [5]. It is the result of a $45, \mathrm{X}$ monosomy karyotype (60\%), a 45,X/46XX mosaicism (30\%) or a normal 46XX karyotype with structural abnormality of the second X chromosome [6]. Though no clear psychiatric component is associated with TS, the clinical manifestations of certain neuropsychiatric disorders have been well documented in patients with TS [7]. Only one case report has previously documented TS mosaicism and OCD; no monosomy karyotype or structural abnormality of the second $\mathrm{X}$ chromosome cases were found in the literature [8].

\section{Case Report}

A 19-year-old female with TS with past psychiatric and medical history of bipolar I disorder, anorexia nervosa (binge eating/ purge type), attention deficit hyperactivity disorder (ADHD), bicuspid aortic valve, scoliosis and hypothyroidism presented to the office for management of OCD. The patient's progress in school had been tracked since 2009, noting that she was doing well and had many friends; however, she was beginning to struggle in school. In 2010, she was hospitalized for the clinical manifestations of anorexia nervosa, requiring nutritional rehabilitation and psychiatric intervention. In 2011, the patient exhibited OCD behaviors for the first time, specifically obsessions for cleanliness and symmetry. Over the next 4 years, her symptoms progressed. She was referred to psychiatry for a severe exacerbation of her obsessions and compulsions that left her incapacitated. The patient's only psychiatric medication on presentation was lithium $450 \mathrm{mg}$ twice a day.

Regarding social history, the patient is the only child of parents who are unrelated. The only known family psychiatric history was self-reported anxiety in her mother and maternal 
grandmother.

On examination, the interview revealed an alert, listless and calm adolescent who quickly became anxious and guarded upon interview. The patient took about $30 \mathrm{~s}$ to sit down in her chair, moving up and down while whispering a numeric count under her breath. Furthermore, she showed signs of mental compulsions (whispering to herself repeatedly) while battling physical compulsions, manifesting as repeated hand movements throughout the interview. The patient's mother confirmed several compulsions, including debilitating bathroom rituals involving wiping before and after defecation, hand washing routines and scrubbing to the point of bleeding when showering; this was all reported to be in response to patient's obsession with cleanliness. Of note, the patient has also engaged her family members in rituals, asking her mother to step in and out of doorways, repeatedly. Interestingly, it became apparent on interview that certain obsessions were not entirely ego-dystonic; patient noted ego-syntonic experiences with her less intrusive thoughts about symmetry. Upon interview conclusion, children's Yale-Brown obsessive compulsive scale (CY-BOCS) was performed to further delineate patient's OCD severity and document baseline symptoms [9]. CY-BOCS defines the following ranges: $0-7$ subclinical, 5 - 15 mild, 16 - 23 moderate, 24 - 31 severe, and 32 - 40 extreme [10]. The patient's obsession subtotal was $16 / 20$, compulsion subtotal was $15 / 20$ and overall score was $31 / 40$, which correlates with severe OCD [10].

The patient had a gradually worsening course. Due to comorbid bipolar disorder with OCD, we avoided usual SSRI/ clomipramine use, as those treatments would often lead to mood instability. The patient was lost to follow-up and we were unable to determine her karyotype. Her parents decided to relocate to another country where there was more family support to assist with her care.

\section{Discussion}

In a patient with both a genetic syndrome and multiple psychiatric comorbidities, it is important to consider what may have escalated the patient's predisposition to OCD development/ exacerbation. This patient was at a significantly increased risk for the development of OCD given her past psychiatric history of bipolar disorder I, anorexia nervosa and ADHD [11]. In a study of 3,372 OCD subjects treated in specialist health care, $70.8 \%$ of males and $74.8 \%$ of females were diagnosed with at least one additional psychiatric or neurodevelopmental disorder, with anxiety (odds ratio (OR): 1.78), depressive disorder (OR: 2.03), eating disorder (OR: 5.66) and bipolar disorder (OR: 1.78) having the highest odds of co-existing [11].

By virtue of her genetic condition, the patient was already at increased risk for psychiatric disease, though no psychiatric component to the chromosomal syndrome has been described [7]. Neuropsychiatric symptoms in women with TS include mood disorders (major depression and bipolar disorder), anxiety (post-traumatic stress disorder and panic subtypes most prevalent) and eating disorders [12]. Specific learning disabilities such as mild mental retardation, arithmetic and visuospa- tial processing deficits represent the cognitive phenotype of this genetic syndrome [13]. Less commonly described psychiatric comorbidities in TS patients include schizophrenia, psychosis and ADHD [14].

Given the increased incidence of OCD in both mood disorders and eating disorders, the authors postulate that the patient's genetic makeup and psychiatric comorbidities had a synergistic effect in her developing OCD. Thus, OCD in patients with TS may be more common than currently recognized and presently underdiagnosed. Of note, the potential for developmental delay in these patients may result in older patients describing obsessions as ego-syntonic, as briefly described in our patient. One study on OCD in children and adolescents found that $16 \%(\mathrm{~N}=110$, mean age 10.22) displayed ego-syntonic obsessions [15]. Thus, it is especially important for the treating clinician to treat TS patients by developmental stage rather than chronological age.

The authors would also like to point out a possible genetic link between TS and OCD via the $\mathrm{X}$ chromosome. As previously mentioned, there are studies linking genes on the $\mathrm{X}$ chromosome to OCD in families with multiple hoarding members [16]. Samuels et al note statistically significant $(P=0.002)$ signals on the $\mathrm{X}$ chromosome, suggesting this possible link [17]. Given our findings of OCD in a patient with TS, future research should continue to investigate a potential gene linkage via the $\mathrm{X}$ chromosome.

In conclusion, clinicians should attempt to expand the search for psychiatric comorbidity, including OCD, in patients with TS and obtain psychiatric consultation for appropriate behavioral and psychopharmacological management.

\section{Sources of Support}

None.

\section{Conflict of Interest}

None.

\section{References}

1. Hirschtritt ME, Bloch MH, Mathews CA. Obsessivecompulsive disorder: advances in diagnosis and treatment. JAMA. 2017;317(13):1358-1367.

2. American-Psychiatric-Association. Diagnostic and statistical manual of mental disorders: Dsm-5. American Psychiatric Publishing, Incorporated: 2013.

3. Pittenger C, Kelmendi B, Bloch M, Krystal JH, Coric V. Clinical treatment of obsessive compulsive disorder. Psychiatry (Edgmont). 2005;2(11):34-43.

4. Nestadt G, Grados M, Samuels JF. Genetics of obsessive-compulsive disorder. Psychiatr Clin North Am. 2010;33(1):141-158.

5. Gravholt $\mathrm{CH}$. Clinical practice in Turner syndrome. Nat Clin Pract Endocrinol Metab. 2005;1(1):41-52. 
6. Kesler SR. Turner syndrome. Child Adolesc Psychiatr Clin N Am. 2007;16(3):709-722.

7. Catinari S, Vass A, Heresco-Levy U. Psychiatric manifestations in Turner Syndrome: a brief survey. Isr J Psychiatry Relat Sci. 2006;43(4):293-295.

8. Archana V, Sarada K. Turner's syndrome and obsessive compulsive disorder - a case report. IOSR Journal of Dental and Medical Sciences. 2014;3:24-27.

9. Storch EA, Murphy TK, Adkins JW, Lewin AB, Geffken GR, Johns NB, Jann KE, et al. The children's Yale-Brown obsessive-compulsive scale: psychometric properties of child- and parent-report formats. J Anxiety Disord. 2006;20(8):1055-1070.

10. Wu Y, Lang Z, Zhang H. Efficacy of Cognitive-Behavioral Therapy in Pediatric Obsessive-Compulsive Disorder: A Meta-Analysis. Med Sci Monit. 2016;22:1646-1653.

11. Rintala H, Chudal R, Leppamaki S, Leivonen S, HinkkaYli-Salomaki S, Sourander A. Register-based study of the incidence, comorbidities and demographics of obsessivecompulsive disorder in specialist healthcare. BMC Psychiatry. 2017;17(1):64.

12. Cardoso G, Daly R, Haq NA, Hanton L, Rubinow DR, Bondy CA, Schmidt P. Current and lifetime psychiatric illness in women with Turner syndrome. Gynecol Endo- crinol. 2004;19(6):313-319.

13. Mazzocco MM. The cognitive phenotype of Turner syndrome: Specific learning disabilities. Int Congr Ser. 2006;1298:83-92.

14. Knickmeyer RC, Davenport M. Turner syndrome and sexual differentiation of the brain: implications for understanding male-biased neurodevelopmental disorders. J Neurodev Disord. 2011;3(4):293-306.

15. Tanidir C, Adaletli H, Gunes H, Kilicoglu AG, Mutlu C, Bahali MK, Aytemiz T, et al. Impact of gender, age at onset, and lifetime tic disorders on the clinical presentation and comorbidity pattern of obsessive-compulsive disorder in children and adolescents. J Child Adolesc Psychopharmacol. 2015;25(5):425-431.

16. Samuels JF, Bienvenu OJ, Pinto A, Murphy DL, Piacentini J, Rauch SL, Fyer AJ, et al. Sex-specific clinical correlates of hoarding in obsessive-compulsive disorder. Behav Res Ther. 2008;46(9):1040-1046.

17. Samuels J, Shugart YY, Grados MA, Willour VL, Bienvenu OJ, Greenberg BD, Knowles JA, et al. Significant linkage to compulsive hoarding on chromosome 14 in families with obsessive-compulsive disorder: results from the OCD Collaborative Genetics Study. Am J Psychiatry. 2007;164(3):493-499. 